\title{
Rethinking creative intelligence: comparative psychology and the concept of creativity
}

\author{
Henry Shevlin ${ }^{1}$ \\ Received: 15 December 2019 / Accepted: 14 October 2020 / Published online: 17 December 2020 \\ (C) The Author(s) 2020
}

\begin{abstract}
The concept of creativity is a central one in folk psychological explanation and has long been prominent in philosophical debates about the nature of art, genius, and the imagination. The scientific investigation of creativity in humans is also well established, and there has been increasing interest in the question of whether the concept can be rigorously applied to non-human animals. In this paper, I argue that such applications face serious challenges of both a conceptual and methodological character, reflecting deep controversies within both philosophy and psychology concerning how to define and apply the concept of creativity. After providing a brief review of some of the leading theories of creativity (Section 2) and discussing some of the strongest putative cases of creative intelligence in non-human animals (Section 3), I examine some of the more worrisome difficulties faced by attempts to use these theories to answer the question of whether animals are truly creative (Section 4). I conclude by examining how we might overcome them, and suggest that one approach worth taking seriously is to adopt what I term a Strong Rejectionist view of creativity, eschewing use of the term entirely in the scientific study of comparative cognition.
\end{abstract}

Keywords Creativity $\cdot$ Comparative psychology $\cdot$ Philosophy of science $\cdot$ Animal cognition $\cdot$ Creative intelligence $\cdot$ Creative cognition $\cdot$ Insight

\section{Introduction}

Creativity is a concept deeply rooted in folk psychology and is applied widely to a broad array of human activities. We praise children for their creative imagination, seek

This article belongs to the Topical Collection: Creativity in Art, Science \& Mind Guest Editors: Adrian Currie, Anton Killin

Henry Shevlin

hfs35@cam.ac.uk

1 Leverhulme Centre for the Future of Intelligence, University of Cambridge, 16a Mill Lane, Cambridge CB2 1SB, UK 
to unleash the power of our creativity in the workplace, and admire creative geniuses in the arts and sciences. Reflecting the central place of creativity in human thought, a formidable body of literature on its nature and underlying mechanisms has developed in a wide range of fields including psychology, philosophy, neuroscience, the history of art, and anthropology.

While much of the interest in creativity has focused on creativity in humans, it has also long been suggested that some non-human animals might also be creative, and examples abound of apparent innovation, improvisation, and ingenuity in animal groups as varied as chimpanzees, dolphins, and birds. Despite the abundance of evidence of prima facie creative behaviour in non-human animals, however, the exemplary cases of creativity such as scientific discovery and artistic inspiration are confined to distinctively human forms of life, and there consequently remains considerable disagreement within cognitive science as to whether (and in what sense) any non-human animals are capable of "true" creativity. ${ }^{1}$

This paper examines our prospects for answering this question. I begin in Section 2 by briefly spelling out some of the leading approaches to creativity. In Section 3, I provide a condensed survey of some of the most spectacular feats of apparent creativity in animals. In Section 4, I consider some of the profound challenges that arise when we bring these together and attempt to apply our theories of creativity to prima facie instances of creative behaviour in animals. Finally, in Section 5, I conclude by suggesting that the best way for comparative psychologists to proceed may be to abandon the concept of creativity all together, and to focus instead on developing and applying frameworks that make use of narrower and more tractable operationalised concepts such as behavioural plasticity, neophilia, and learning.

I would finally note in proceeding that we apply the adjective 'creative' to an unusually wide variety of different entities and processes, including artefacts, societies, individuals, actions, and particular cognitive processes. In what follows, I will use the terms "creative" and "creativity" specifically in regard to what Boden (1996) and Kronfeldner (2009) call psychological creativity, or what I will term "creative intelligence." Broadly speaking, I take this notion to pick out the kinds of cognition that underpin common exemplars of creative thought and behaviour, such as acts of the imagination, ingenious reasoning and problem solving, and curiosity, play, and exploration.

\section{Theories of creativity}

Before considering the question of whether animals can exhibit true creativity in this sense, it will first be helpful to provide a very brief summary of some of the leading theories that have attempted to pin down its definitive characteristics. Two such characteristics are relatively uncontroversial: in order to count as creative, a given thought and behaviour must be novel and valuable. ${ }^{2}$ However, most theorists recognise

\footnotetext{
${ }^{1}$ For recent volumes discussing apparent innovation and creative intelligence in non-human animals, see, e.g., Reader and Laland (2003) and Kaufman and Kaufman (2015).

${ }^{2}$ See Feist (1998): "for the last 30 years or more, creativity researchers have been nearly unanimous in their definition of the concept... [c]reative thought or behavior must be both novel-original and useful-adaptive."
} 
that there is more to creativity than just these two conditions. After all, someone might adopt an innovative strategy that yields valuable rewards simply by chance, for example via simple trial-and-error or serendipity (see, for example, Novitz 1999 on Charles Goodyear's chance discovery of vulcanised rubber).

For this reason and others some third criterion is usually added to the definition of creativity. ${ }^{3}$ Complicating matters, however, a wide variety of such conditions have been proposed. For the purposes of convenience, I will group these proposals into four main categories. These categories are not intended as a definitive or exhaustive analysis of the fault-lines between different approaches to creativity, but rather as a heuristic taxonomy to give readers a feel for some of the variety among leading views. Note also that the characterisations that follow are deliberately brief, reflecting the broader goal of the paper to examine methodological issues in the application of theories of creative intelligence to animals rather than to engage with particular theories. ${ }^{4}$

The first set of views that can be singled out are those that take creativity to be individuated in part by the experience of the creative agent. Boden, for example, has argued at length that in addition to being novel and producing valuable outputs, a creative thought or action must be in some sense surprising (Boden 1996, 2004, 2010, 2014). In its emphasis on the subjective character of creative intelligence, Boden's view of creativity is related in spirit to another longstanding approach to creative intelligence that identifies it with a special kind of feeling or attitude undergone when arriving at creative solutions and judgments, namely the feeling of insight or the "aha! moment" (Hutchinson 1941; Kounios and Beeman 2009).

A second set of views place an emphasis not so much on the experience of creative discovery but rather on the exercise of certain psychological capacities in creative action. Such a view has been developed in great detail by Berys Gaut, who argues that the novelty and value conditions be supplemented by the constraint that creative actions involve what he calls flair, where this is shorthand for an action having "a relevant purpose... some degree of understanding... a degree of judgement... and an evaluative ability directed to the task at hand" (Gaut 2010). Other views that place an emphasis on creative action include that of Paul and Stokes (2018), who identify intentional agency as criterial for creative action.

In at least superficial contrast to views that link creativity to explicit goals and purposes, a third set of approaches see creativity as being importantly different from typical goal-directed behaviour. Kronfeldner (2009, 2018), for example, argues that spontaneity is critical for creative thought, taking this to refer to "a certain independence from the intentional control and the previously acquired knowledge of the person whose creativity is at issue." Other proposals that emphasise the difference between creative intelligence and other forms of intentional behaviour include that of Amabile (1996), who argues that creative processes must operate as heuristics for problemsolving rather than explicitly represented solutions. ${ }^{5}$

\footnotetext{
${ }^{3}$ Other motivations for identifying a third criterion include a desire to exclude cases of 'dark creativity' such as ingenious torture techniques as well creativity emerging from inanimate processes such as plate tectonics. See Gaut (2010) for a discussion of this issue.

${ }^{4}$ For recent volumes on approaches to creativity in philosophy and cognitive science see, e.g., Kaufman and Paul (2014) and Gaut and Kieran (2018).

${ }^{5}$ One might also include with such views Koestler's (1964) famous model of creative thought as involving "bisociation", or the bringing together "of two self-consistent but habitually incompatible frames of reference."
} 
A final kind of approach to creativity worth noting here stems has focused on the temporal sequence of the creative process, arguing that truly creative thought or behaviour must follow a particular series of cognitive steps. One historically important set of views (defended by, e.g., Wallas 1926, and Hadamard 1954) drew upon the introspective reflections of Henri Poincaré (1952) about the process of mathematical discovery to argue for four-step views of creativity, in which creative insights rely on initial stages of preparation and incubation, followed by a moment of inspiration and subsequent verification. More recently, two-step views of the creative intelligence have been developed and defended by psychologists. Among the most influential are the models of Campbell (1960) and Simonton (2009), which claim that creativity must involve an element of randomised or "blind" variation followed by selective retention of the most valuable ideas. A related important two-step framework is the generate-andexplore or "geneplore" (Finke et al. 1992; Ward et al. 1999), which breaks down the creative process into an initial period in which ideas and structures are initially generated and a subsequent period of exploration and implementation.

\section{Creative intelligence in non-human animals}

The foregoing discussion hopefully provides a reasonable primer and summary of some of the leading approaches to creativity. However, as the reader may have noticed, almost all of these approaches take as their main explanandum specifically human creativity, with the dizzying accomplishments of great artists and scientists in some cases serving as their primary exemplars. This reflects a tradition of thought about creative intelligence in which it seen as a defining human accomplishment, both for individual geniuses and for our species as a whole. As Carruthers and Picciuto (2014) note, if we take many theories of creativity at face value, "creativity appears to be uniquely human... Indeed, it seems to be fairly rare even among humans."

It must be acknowledged that the breadth and scope of human creative output - from Picasso to Frank Lloyd Wright - is unique among animal species, and even ubiquitous forms of human behaviour such as the creation of representational art may constitute fairly recent innovations in our evolutionary history (Morriss-Kay 2010). Nonetheless, there are several reasons why we may wish to reconsider this conception of creativity as exclusively human.

For one, many of us are happy to describe the feats of even young children as creative, from their first faltering attempts at smearing paint on a piece of paper to their various forms of social play (Bateson and Martin 2011). Given that we naturally countenance such relatively untutored behaviour as creative, it does not seem outrageous to think that there may be equivalent (if less immediately visible) forms of creative intelligence in some non-human animals.

For another, many will be sympathetic to Charles Darwin's incrementalist view of the mind, according to which between humans and animals there exists "no fundamental difference between man and the higher mammals in their mental faculties", but rather an "interval [that] is filled up by numberless gradations" (Darwin 1880). If this (admittedly controversial) picture of the evolution of human cognition is correct, then we might consider it possible or even likely that some non-human animals to exhibit at least rudimentary forms of creative intelligence. 
Any discussion of the question of creative intelligence in non-human animals, however, must be primarily directed towards the rich observational data from an enormous range of species collected by biologists and ethologists over the last century. In the present section, then, I will briefly summarise a select few examples of putatively creative behaviour in non-human animals, with a view to demonstrating both the sheer variety of such behaviour and its compelling status as intuitively creative. What follows is not, of course, intended as a rigorous survey, but should hopefully serve as an edited "highlights reel" that may be of interest to those whose primary focus has hitherto been on specifically human creativity.

\subsection{Insight}

Some of the earliest and most influential work on non-human creativity comes from Wolfgang Köhler's landmark studies on problem-solving in chimpanzees (Köhler 1925). Operating within the contentious and relatively new field of comparative psychology in a climate shaped by the works of scientists like Morgan, Romanes, Thorndike, and Hobhouse, Köhler examined the chimps' ability to solve problems that demanded some foresight, planning, or intelligence. In the most famous of these, chimpanzees were placed in a room containing boxes and bananas hanging out of reach, and after initially trying (and failing) to reach the bananas via leaping, some of them hit upon the solution of moving the boxes and climbing up on them to reach the reward. In addition to demonstrating a certain degree of intelligence, the successful chimpanzees' behaviour also showed tantalising similarities to insightful human problem-solving (held by many to be an exemplary form of creative behaviour), in particular their tendency to solve the problem only after standing still and looking at the bananas for an interval before suddenly hitting upon a solution.

Though Köhler's work may have lacked some of the experimental controls that we would expect in modern animal studies, similar results were obtained with chimpanzees by Schiller (1957) and with pigeons by Epstein et al. (1984). More recently, seeming cases of insightful problem-solving - understood here as successful problemsolving that arises after an impasse and involves some degree of restructuring or reconceptualising of a context - have been documented in a wide range of species, including ravens (Heinrich 1995), rats (Durstewitz et al. 2010), and orangutans (Mendes et al. 2007).

Nonetheless, questions about animal insight remain controversial for multiple reasons. One is the apparent residual role for reinforcement learning even in cases of apparent insight (Taylor et al. 2010). Whether this means that the behaviour in question falls short of genuine insight depends upon much broader theoretical and scientific questions concerning the role of associative learning in intelligence (see Shettleworth 2010 and 2012 for discussion). Another issue is the fact that in paradigms like Köhler's, animals seem able to arrive at novel solutions only if their component behaviours are either within their normal repertoire or have been specifically reinforced (Epstein et al. 1981), perhaps suggesting they are incapable of arriving at truly novel solutions. A final issue concerns the fact that insight in humans is typically associated with a specific kind of emotional reaction. As Shettleworth (2012) notes, "[c]omplicating matters for testing non-verbal creatures, the acid test of insightful problem solution in people is its 
distinctive phenomenology, the "aha" experience" (note the direct connection here between insight and the first family of views discussed in Section 2).

\subsection{Improvisation}

Along with insight, the capacity to improvise is naturally associated with creativity; certainly, many of us would feel our creative capacities would be harshly tested were we to be forced to appear on stage without preparation at a comedy night or "ad lib" a speech at a wedding. As in the case of insight, there is a large body of data claiming improvisation exists and is even commonplace in non-human animals. Improvisation is defined in various ways in animal behaviour research, but here I will use the helpful formulation of Russon et al. (2010), who identify it with "on the spot, spontaneous solutions to a task facing the actor."

As a starting point for evidence of improvisation in animals, we might look at the many cases of startlingly novel behaviours adopted by species in response to novel environmental contingencies. To give one recent example, Mientian tree frogs in Taiwan have taken to using storm drains to enhance the volume and duration of their mating calls (Tan et al. 2014), seemingly showing an ability to adapt behaviour to novel environmental contingencies. Other famous cases include the discovery that great tits in the UK had learned to peck through the lids of milk bottles to drink the cream inside (Hinde and Fisher 1951) and the emergence of the novel behaviour among Japanese macaques of washing off soil and debris from sweet potatoes (Kawai 1965). Unsurprisingly, there is also a rich body of evidence concerning improvisational navigation and arboreal travel techniques and tool use in ape species (see, e.g., Sugiyama and Koman 1979; Russon et al. 2015).

One of the most compelling and influential demonstrations of improvisational behaviour in animals comes from the extensive work of Karen Pryor (1999), who developed training techniques to reward novel and spontaneous actions. For example, in work with Rough Toothed Porpoises, no cue for reward was initially provided to the animals, but rewards were presented whenever the animals performed some new action (such as a backflip) not within their existing observed repertoire. The porpoises quickly seemed to "cotton on" to what was expected of them, producing a large number of previously unseen behaviours (Pryor et al. 1969; Pryor 2000). This procedure - dubbed "101 things to do with a box" - has since been used successfully in a variety of animals, including other marine mammals and dogs.

Interpretation of all such behaviours is complex and vexed (Kaufman and Kaufman 2004). To note just one issue, it seems likely that many improvisational behaviours such as great tits piercing of milk bottle lids initially involved a chance action (perhaps involving a bird pecking at an insect that had landed on a milk bottle) that was subsequently reinforced and later acquired by other members of the species via social learning. In this sense, many apparent cases of improvisation may involve a strong element of serendipity rather than foresight. Given the broader uncertainty concerning the relevant cognitive mechanism underlying these behaviours, then, we cannot clearly say which of 
the putative criteria for creativity discussed in Section 2 they satisfy. Moreover, even if the specific mechanisms were identified, whether the behaviours would constitute genuine instances of creative intelligence would of course depend on which particular criteria one adopted. ${ }^{6}$

\subsection{Physical problem-solving}

Some of the most striking examples of animal ingenuity in recent work on animal behaviour come from the rich patterns of complex problem-solving found in many bird species, most notably among corvids and parrots (see Auersperg 2015 for a review). These include using the animals using multiple context-appropriate tools and modifying them to suit the demands of particular tasks (Bird and Emery 2009a). In one famous example of the latter, for example, a New Caledonian crow known as Betty spontaneously bent a straight piece of wire into a hook into order to retrieve a food reward (Weir et al. 2002).

Extensive research has also been conducted to investigate birds' capacity to engage in complex multi-step problem-solving, often using specially designed "puzzle boxes" that require a sequence of different physical manipulations to open. While some training time is usually required for success in such tasks, birds are frequently able to repeat the steps exactly after an initial success, and once familiar with a puzzle box react appropriately to changes in its layout, for example ignoring locks that were previously part of tasks but have since become irrelevant (Auersperg et al. 2013). Parrots such as cockatoos and keas are frequently the stars of these demonstrations, and a dramatic account of one such bird is provided by Auersperg (2015) as follows.

In the most extreme case a male captive Goffin cockatoo Pipin, lacking previous training, dismantled a sequence of five unfamiliar locks in $100 \mathrm{~min}$ total trial time... His actions encompassed pulling up a pin, unscrewing a bolt from a nut, pressing a cylinder through a ring, fitting a perforation in a wheel-shaped lock through a t-bar and pushing a bar-lock open.

Another impressive demonstration of ingenious physical reasoning in animals comes from so-called "Aesop's Fable" tasks. In brief summary, this task requires an animal to raise the water level of a container to access a reward. In one version of this paradigm, orangutans (Mendes et al. 2007) and chimpanzees (Hanus et al. 2011) are able to do this by sucking up water from a dispenser and spitting it into a container. Another variant of the task requires animals to drop stones or other small objects into a tube to accomplish the same result. Rooks, Eurasian jays, and New Caledonian crows all

\footnotetext{
${ }^{6}$ An anonymous reviewer helpfully suggests that a provisional criterion for a creative behaviour may be it that cannot explained away merely in terms of reinforcement learning. While I have some sympathy for this suggestion, it is not clear to me that a behaviour's having been produced by reinforcement learning rules out the possibility that it is appropriately described as creative. After all, there is a long tradition - from Thorndike to Skinner to contemporary connectionism - that takes even sophisticated forms of human cognition to ultimately be grounded in principles of reinforcement and association; as Thorndike boldly claims, "the higher animals, including man, manifest no behaviour beyond expectation from the laws of instinct, exercise, and effect; the human mind [does] no more than connect in accord with original bonds, use and disuse, and the satisfaction and discomfort resulting to the neurones" (Thorndike 1911: 274).
} 
perform well in this condition, and seem to demonstrate sensitivity to the physical properties of the relevant objects, preferentially dropping solid as opposed to hollow objects into the tube (Bird and Emery 2009b; Jelbert et al. 2014). Summarising some of their results, Jelbert et al. note that "New Caledonian crows possess a sophisticated, but incomplete, understanding of the causal properties of displacement, rivalling that of 57 year old children."

Sophisticated problem-solving like that discussed above is undeniably clever, and bespeaks a certain degree of intuitive understanding of causal relationships, but still we might wonder whether it is truly creative. While keas are expert object manipulators in the laboratory, for example, they also use their beaks for a wide variety of physical problem-solving tasks in the wild, from cracking open nuts, to overturning stones to look for food, and manipulating tree roots to build nests in crevices. Given such predilections, a sceptic might suggest that they are not doing anything truly novel. Indeed, one meta-analysis of Aesop's fable studies suggested that corvids' performance in the task can be explained via trial-and-error learning coupled with innate preferences for interacting with certain kinds of functional objects (Hennefield et al. 2019). Similarly, even Betty's startling modification of wire tools has been linked to similar bending of twigs carried out by wild New Caledonian crows (Rutz et al. 2016). In order to satisfy the sceptic and settle whether her behaviour truly counts as creative, then, we must return to theoretical issues.

\section{Applying theories of creativity: Challenges and pitfalls}

The brief survey just provided only begins to scratch the surface of the many innovative, flexible, and ingenious behaviours documented across myriad animal species, and even in regard to the cases mentioned, much more could be said. Nonetheless, I am hopeful that the examples discussed illustrate some of the variety of putatively creative behaviour in animals. But is this evidence of true creativity in animals, or merely some weaker notion such as versatility or intelligence? While it is true that many animal researchers would happily demur on this question, preferring to focus on more narrowly scientific notions such as improvisation and neophilia, it is clear that many seek to answer it head on, and as should be clear from the foregoing discussion, it is hard to settle this question on the basis of behaviour alone. ${ }^{7}$ Still, one might hope that there is still fairly straightforward way to answer this question, namely to take our best current theories of creativity and see if behaviours like those mentioned above satisfy their demands.

We should not expect such a project to be simple in practice, of course; ascriptions of any mental state to non-human animals are complex and vexed, and frequently require considerable ingenuity in experimental design to distinguish between different hypotheses, as demonstrated for example by the longstanding controversy concerning whether chimpanzees have a theory of mind (Call and Tomasello 2008). However, in

\footnotetext{
${ }^{7}$ For recent scientific work explicitly engaging with the question of whether animals are capable of creativity per se (as opposed to narrower notions such as improvisation, neophilia, insight, etc.), one can do no better than the wide-ranging and frequently philosophically engaged discussions in Kaufman and Kaufman (2015). Other recent examples of scientific work include Kaufman et al. (2011); Kolodny et al. (2015), and Kuczaj (2017)
} 
the present section, I will argue that the difficulties faced by attempts to apply our theories of creativity to non-human animals are unusually profound, and make the question far harder to address than many ostensibly similar debates in comparative psychology. While I do not regard any of the problems discussed below as decisive, when taken together I suggest that they motivate us reconsider the suitability of creative intelligence as a scientific concept in comparative psychology, a proposal developed in the following section. ${ }^{8}$

\subsection{Disagreement about definitions}

As noted in Section 2, there are a wide number of different theories of creative intelligence which place emphasis on quite distinct aspects of cognition and behaviour. This presents an immediate and obvious challenge for researchers concerned with the question of whether animals can be genuinely creative: depending on which theory we adopt, we may come to quite different conclusions about the distribution of creative intelligence in nature. As Chen (2018) notes, the "lack of agreement among creative cognition researchers about the necessary and/or sufficient conditions for creativity... is worrying because the criterial definition that one accepts can significantly influence the way one goes about analyzing creative phenomena."

The presence of competing theories concerning a phenomenon is not by itself a grave concern for the viability of its investigation, of course. After all, the history of science is replete with deep theoretical disputes, as was the case in the debate concerning whether light is best understood as a wave or a particle or the stillongoing controversy concerning the significance of kin selection in evolution (Birch and Okasha 2015). We may hope, as Kronfeldner (2018) does, that while "[c]reativity is hard to explain, like the weather... [a]s science has made progress with the latter, it will make progress with the former as well."

There is some reason to think, however, that research on creativity faces deeper challenges than a mere lack of evidence or incomplete models. In contrast to many other scientific controversies, there is little agreement about how to even define or otherwise identify the very phenomenon we are interested in. To give just one example of these definitional disputes, consider the question of whether creative output must be valuable. While, as noted above, this is commonly assumed in much psychological and philosophical research, it is far from unquestioned. Hence Weisberg (2015), concerned with the tendentious and subjective nature of ascriptions of value, suggests that "any novel product, produced intentionally, is creative, regardless of whether it is ever of value to anyone." A similar claim is made on different grounds by Hills and Bird (2018), who argue that we can recognise creative outputs without assigning them value, and moreover, that we have reason to believe a similar disposition is at work in many of both the valuable and valueless productions of creative thinkers. On these grounds, they argue that "creativity can produce objects without value of any kind."

\footnotetext{
${ }^{8}$ Much of the following discussion draws upon Chen's (2018) criticisms of what he terms the "bundles-ofcriteria" conception of creativity. However, whereas Chen is primarily concerned with human research on creativity, however, here my focus is on the (in my view, even greater) challenges for applying theories of creativity to creative cognition research in non-human animals.
} 
This is a single example of the fundamental criterial disputes running through analytical work on creativity, but there are many others, including the question of whether creativity must involve surprise (Audi 2018: 26), whether creativity must involve authentic expression of one's own values (Kharkhurin 2014), and whether creativity should be understood as fundamentally an unconscious process (Russ 1993), a wholly conscious one (Pressing 1988), or a mixture of both (Gaut 2003; Baumeister et al. 2011).

It might be objected that similar deep-seated conceptual and definitional disagreements dog other contemporary projects of scientific and philosophical significance. In short-term memory research, for example, we find a proliferation of competing models (Shevlin 2020), while in philosophy fundamental disagreement is the norm in fields such as ethics and the study of consciousness. ${ }^{9}$ Yet there are arguably important factors that distinguish these cases from that of creativity. In memory research, for example, there is at least relatively clear agreement as to the concept of memory itself, as well as some convergence on tasks such as the n-back test that place demands upon it. In creativity research, by contrast, even these forms of consensus are elusive. And while deep disagreements on fundamental issues may dog normative ethics and the study of consciousness, the centrality of ethical reasoning in human life and the special firstpersonal relationship we have to consciousness arguably give us special reasons to vindicate or at least reconstruct some of our pretheoretical concepts and judgments. By contrast, it is less clear that we must be committed to defending the importance of the concept of creativity, or forging robust links between the folk concept and scientific usages of the term. ${ }^{10}$

In any case, what I wish to emphasise for present purposes is that in light of basic theoretical disputes in the theory of creativity, questions about whether animals may exhibit creative intelligence are likely to be challenging to resolve. The situation is particularly worrisome in light of the fact that in the human case, we can at least agree on some familiar exemplars of creativity, even if intuitions about special cases may vary. By contrast, no such agreement can be found regarding examples like those discussed in Section 3, as demonstrated by the fact that some researchers deny the existence of creativity in non-human animals at all (Fuentes 2017).

\subsection{Interpretative challenges and value ladenness}

I have suggested that the lack of consensus concerning definitive criteria for creative intelligence poses a significant problem for interpreting putative instances of creativity in animals. I now wish to suggest that even were we to possess such criteria, applying them would be far from easy. To begin with, consider the idea that creative behaviour must be novel, at least to the individual performing it. This is arguably the least

\footnotetext{
${ }^{9}$ Though of course, the existence and extent of disagreement in normative ethics has been a historically important argument for many defenders of moral relativism; see e.g., Prinz (2007) for discussion. Likewise, many regard the extent of cross-purpose and confusion in debates about consciousness as suggestive of deep problems in the debate (e.g., Güzeldere 1997).

${ }^{10}$ Admittedly, if it were shown that an animal possessed a high degree of creative intelligence (in some intuitively uncontroversial sense), we might be inclined to assign it greater ethical consideration. However, the relationship between creativity and ethical status strikes me as relatively indirect and vexed compared to the direct and (relatively) uncontroversial ethical significance of consciousness.
} 
controversial criterion for creativity, and it closely tracks our intuitions about what constitutes as creative, insofar as repetitive actions strike us as uncreative while highly innovative behaviour is frequently (though not always) an exemplar of creativity.

Despite the relative consensus that some element of novelty or innovation is required for creativity, however, there are serious challenges in using it as a criterion to assess any given behaviour. To illustrate the point, consider the difficulty involved in pinning down what exactly makes a given act innovative (and hence potentially creative). Thus imagine a standup comedian weighing up which joke to use to open her set in light of the anticipated sensibilities of her audience, or a creative jazz musician who routinely improvises in his performance. In both of these cases, it is possible to read the individuals as doing nothing strictly new: the comedian may have told all the jokes in her repertoire many times, while the jazz musician routinely engages in improvisation. Yet both cases strike us as at least potentially involving clear elements of creativity.

An obvious rebuttal to these cases is that the decision-making processes involved still involve a degree of novelty: after all, no two comedy audiences or jazz improvisations are alike. However, this makes plain a serious methodological challenge for assessing innovation, specifically a worry concerning the appropriate fineness of grain to adopt in individuating specific behaviours and contexts. If we adopt an extremely fine-grained account and treat any behaviour as novel if an individual has never performed the exact same action in the exact same circumstances in the past, then natural variations in performance will mean that innovative behaviour will be ubiquitous. By contrast, if we individuate behaviours coarsely and treat a behaviour as innovative only if it falls under a wholly new basic category, then true innovation will be extremely rare if not impossible: a painter or poet trying out a new form could still be said to be painting or composing, rather than engaging in a truly novel activity. ${ }^{11}$

This may seem like an idle philosophical quibble; in practice, after all, we are usually able to decide whether a given human behaviour should count as innovative or otherwise. However, as was suggested in the foregoing discussion of tool use in birds, matters are much less clear in the case of apparent creativity in animals. Should we count a parrot's manipulation of a puzzle box or a crow's clever manipulation of tools as uncreative on grounds that similar behaviours have been performed in the wild? Without a principled and strict criterion for assessing what counts as true innovation, we will be unable to answer this question, and while we might hold out hopes that philosophers and scientists will settle on such a measure, as matters stand one is lacking.

Somewhat related worries apply to the issue of the valuableness of a given act. While many philosophers have been impressed by Kant's (1987 [1790]) claim that "original nonsense" should not count as creative, as noted above the idea that creative output must be valuable has been recently questioned. Some of this resistance (Kharkhurin 2014; Weisberg 2015) has come from the fact that assessments of value vary both across cultures and between individuals.

\footnotetext{
${ }^{11}$ We might of course embrace a thoroughgoing contextualism about attributions of novelty, accepting that a behaviour may be novel qua one consideration but non-novel qua another. However, as noted, inevitable minor variations in performance mean that there will always be some respects according to which a behaviour might be classified as novel. If we wish to incorporate an account of novelty along these lines into our account of creativity, then, we will in turn be committed to a fairly radical contextualism about creativity itself, a consequence that seems at odds with most leading approaches that seek to identify creativity with specific kinds of cognition and behaviour.
} 
To give a simple example, consider the first awkward attempts by a child at painting or drawing. While we would not consider such works to be valuable for our culture as a whole, the outputs in question might have considerable value for her or her parents. In light of this, we might attempt to identify the relevant notion of value as residing in the attitude of the creative individual towards her own cognitive processes or outputs. However, this again seems a somewhat arbitrary way to flesh out the value criterion. The history of art, after all, is replete with cases of artists who despised their own creations or wished them destroyed, including such masterpieces as Michelangelo Florentine Pieta and Virgil's Aeneid, yet we would not consider them to be uncreative as a result. Likewise, an artist might feel incredibly attached to a work that others considered to be utterly lacking in value.

The issue of how to spell out the value criterion is a complex one in the human case, but it is not clear that it is any easier to settle in the case of animals. Most non-human species are likely to lack the metacognitive capacities required to adopt evaluative attitudes towards their own psychological processes or behaviour, hence if we wish to spell out some notion of value for measuring creative intelligence in animals, it will likely have to be with recourse to some more objective notion, such as its contribution to an organism's survival or reproduction. This might allow us to say, for example, that a crow's problem solving ability is valuable because it helps it obtain food.

This runs into the problems that many of the behaviours we naturally associate with creative intelligence are highly dangerous for animals. This is an issue that has been widely discussed in relation to the distinction between neophilia and neophobia in different species and across individuals (see, e.g., Greenberg and Mettke-Hofmann 2001). Curiosity and exploration, for example, are key elements of many theories of creativity, but the risks they carry vary considerably across species and between environments. A highly exploratory foraging strategy might be extremely adaptive in a context with few predators, while being highly dangerous in a more bloodthirsty ecosystem. Even within a given geographical locale, changes in the abundance and variety of predators can mean that exploration and curiosity become a dangerous strategies. New Zealand's Keas, for example, are highly neophilic birds, perhaps in part because they confronted very few predators (and exclusively avian ones) for much of their recent evolutionary history. In the present day, however, their numbers have plummeted due to non-native predators such as foxes, weasels, and domestic cats, and it is not unreasonable to suppose that their onceadaptive neophilia is now a liability in the face of such new threats. However, this clearly has no bearing on whether or not their problem-solving capabilities should be considered creative. But to stipulate that assessments of the value of a given behaviour should be made on the basis of an organism's natural or evolutionary environment seems similarly flatfooted: we can easily imagine an unusually neophilic animal raised in captivity who displayed forms of exploration and innovation that would be incredibly dangerous or metabolically costly in the wild, yet this would have little bearing on how willing we were to call its laboratory behaviour creative. ${ }^{12}$

I would suggest, then, that even aside from questions of the basic criteria we use for defining creative intelligence, there are serious and perhaps intractable problems of

\footnotetext{
${ }^{12}$ As an anonymous reviewer notes, we may of course be able to classify behaviours as generally fitnessenhancing even if they sometimes lead to adverse outcomes, especially outside ancestral environments. However, as the example at issue aims to illustrate, some plausibly creative behaviours (such as rampant neophilia in a particular specimen of small herbivore) might only be fitness enhancing within highly artificial contexts such as laboratories.
} 
interpretation and application that arise when we attempt to apply notions of novelty and value, and these are only more acute in the case of animals.

\subsection{Measurement problems}

Faced with objections like those above, some readers may note that despite these apparent conceptual challenges involved in defining creativity or interpreting it according to our preferred criteria, there are an abundance of psychometric measures employed for measuring creativity in humans. Consequently, one might think that the conceptual difficulties just discussed cannot be all that grave. Certainly, creative thinking tests are well established and widely employed. Among the most prominent are the Alternative Uses Task (Guilford 1967), the Remote Associates Test (Mednick 1968), and the Torrance Tests of Critical Thinking (Torrance 1980), and there is some reason to think that they provide significant insights into cognitive differences across individuals.

However, I would suggest that the widespread use of these test in professional and educational contexts provides only limited succour to those keen to answer fundamental questions about the nature and distribution of creativity. For one, note that while these tests may track important aspects of cognitive performance, we should not too readily assume that it is creativity per se that they are measuring as opposed to associated capacities such as divergent thinking. This "criterion problem" has been widely discussed by psychologists, notably Amabile (1982), who worried that "many creativity tests do measure abilities that are important for creative performance, but it is unclear whether they are useful for directly assessing something called creativity."

Amabile's own suggestion was for researchers to adopt a "Consensual Definition" that held an action to be "creative to the extent that appropriate observers independently agree it is creative." Whatever the strengths and weaknesses of this proposal, however, it does not seem to have resolved the criterion problem in creative cognition research, as demonstrated by the persistent wide variation among tests of creativity both in respect of their psychometric methods and the associated results from neuroimaging studies. In a 2010 review of 45 neuroimaging studies on creativity employing a range of psychometric techniques, for example, Arden et al. (2010) found little overlap across different tasks in respect of the brain areas involved. This reflected, they suggest, the lack of consensus in the field concerning appropriate psychometric measures for assessing creativity. They conclude that '[ $[\mathrm{t}] \mathrm{he}$ 'criterion problem' in creativity may even have worsened since its discussion in 1982 by Amabile... We cannot interpret, or integrate across, imaging studies that use such diverse creative cognition measures, most of unknown reliability and validity." It is worth stressing that creative cognition researchers are hardly unaware of these problems (Silvia 2007), and there is great interest in developing more robust measures. However, in light of apparent challenges in doing so, one might well wonder whether the problems lie in our very concept of creativity. ${ }^{13}$

\footnotetext{
${ }^{13}$ An instructive comparison in this regard may lie in psychometric measures of general intelligence or " $\mathrm{g}$ factor". Originally proposed by Charles Spearman (1927), g-factor is a proposed unified measure of intelligence, and aims to explain the close correlation between individuals' cognitive performance across a wide range of intelligence tests, a finding that has been called "arguably the most replicated result in all psychology" (Deary 2000). Nonetheless, despite the robustness of g-factor as a psychometric instrument, the very concept of general intelligence and the question of status as natural kind remains deeply controversial (Serpico 2018).
} 
Finally, and perhaps unsurprisingly, I would suggest again that however great the challenges are in developing unified measures of creative intelligence in humans, they are orders of magnitude greater for the project of assessing the existence and degree of creative intelligence in animals. As noted earlier in 3.2, there are procedures like "101 things to do with a box" that have been developed in relation to animals to measure creativity-relevant capacities such as improvisation. But while such tests are of great value for comparative cognition research as a whole, insofar as we wish to use them to identify the presence or absence of creativity per se, we will once again founder on theoretical issues. Putting matters crudely, if we cannot agree on which conceptual criteria, psychometric measures, or patterns of neural activity underlie creativity in our own species, it is unlikely that such consensus will be achievable in the case of animals, not least because of the rich variation in sensorimotor capacities, behavioural dispositions, and cognitive capacities across the natural world.

This is not deny the value of using a diverse battery of cognitive and behavioural measures to assess capacities of non-human animals like innovation, flexibility, causal reasoning, playfulness, and curiosity, as well as more integrated frameworks for assessing the relations between these capacities (see, e.g., Kaufman et al. 2011). However, I would suggest that the most productive conceptual framework for making progress in understanding the kinds of cognition and behaviour with which they are concerned may be one that starts by reconsidering the concept of creativity itself.

\section{Beyond creativity?}

The arguments of the preceding section were largely negative, concerned with what I take to be just a few of the fundamental conceptual and methodological challenges involved in providing a principled definition of creativity and applying it to nonhumans. In this final section, I wish to (all too briefly) consider some of the strategies we might employ for overcoming these worries in the context of questions about which animals if any are truly creative.

One initial proposal (independently endorsed by many of the philosophers and scientists discussed thus far) is to recognise that creativity and creative intelligence come in degrees (e.g., Kronfeldner 2018). This is certainly intuitively plausible, given that we frequently qualify creativity in ascribing it to different people and actions. It has also has the advantage of removing one serious conceptual roadblock to ascriptions of creativity to animals insofar as we are no longer constrained to say of a given nonhuman individual or species that it is or is not creative, allowing us to say instead that it may be creative to some degree. However, insofar as this strategy is intended to be coupled to a notion of creativity as a unified psychological kind, it is subject to many of the same worries already raised. Without a reasonably firm conceptual grasp on creative or clear criteria for applying the concept to non-humans, simply admitting degrees of variation will not give us a clear handle of when and how to apply it.

Another strategy that one might endorse for avoiding some of the problems already discussed is a "divide and conquer" approach that analyses creativity into its component parts. Boden (2004), for example, famously distinguishes between combinational, exploratory, and transformational creativity, while Kaufman and Beghetto (2009) offer a "four-C model" that divides creativity into four categories, dubbed "mini-c", "little- 
c", "pro-C", and "big-C" that aim to track the different forms of innovating, learning, and discovery present in different individuals and lifestages.

Again, this strategy has much to be said in its favour and these are helpful contributions for our understanding of cognition and behaviour. However, I think it is important in offering taxonomies of the varieties of creativity, we must be clear as to whether we are suggesting a strategy for philosophical and linguistic analysis of a folk psychological concept, or instead developing a set of operationalised tools for cognitive science that will, in effect, make reference to creativity unnecessary. Both such endeavours are valuable and important, but they have different goals and methods, and if we fail to be clear about which we are pursuing we run the risk of cross-purpose and confusion. I would also sound a warning that in attempting such decompositions, there is a risk of needless proliferation of distinctions, muddying the waters of an already murky field of inquiry. This is less of a concern for more properly folk psychological projects, insofar as we should expect there to be myriad valuable ways of illuminating different aspects of human values and discourse. Insofar as we wish to make tangible progress in measurement and classification of cognition and behaviour, however, it is important that we endeavour to "carve nature at its joints".

A third proposal for rethinking creativity for which I hold great sympathy is that of Melvin Chen (2018), who argues that we should recognise creativity as a "prototype concept" (in the sense of Rosch 1973). While considerations of space prevent me from doing justice to Chen's view in the present context, in short he proposes that rather than thinking of creativity as a concept whose membership is given by necessary and sufficient conditions, we instead think of it as governed by similarity to central instances, which in the case of creativity might include exemplary feats of imagination and insight. As Chen notes, this may allow us to sidestep or accommodate many of the worries about creativity as a concept, from its value-ladenness to the lack of agreement among creativity researchers about its nature.

As indicated above, I am sympathetic to Chen's suggestions, especially as a strategy for understanding and even quantifying the ways in which the concept of creativity is used in folk psychological contexts. However, I would also suggest that if Chen's approach to understanding the concept of creativity is correct, and its membership is indeed governed by culturally- and context-relative judgments of similarity to exemplars, these features may make it ill-suited to rigorous comparative psychology. ${ }^{14}$

A fourth strategy we might adopt is what I will term a rejectionist one. In short, this holds that we should abandon the concept of creativity for most purposes in cognitive science, and particularly for comparative psychology. There are two possible forms of rejectionism we might consider. Weak rejectionism allows that a comparative science of creative intelligence may one day be possible, while denying that it is currently viable in light of the outstanding controversies concerning the definition and application of the concept. Strong rejectionism, by contrast, would hold that we already have good reason to think that the concept of creativity is inadequate for the purposes of comparative psychological research. Consequently, it would claim, the question of

\footnotetext{
${ }^{14}$ This is a possibility Chen himself recognises, noting that creativity "might well split into a plurality of natural kinds, because different kinds of mental representation that are processed independently must be posited to explain different sets of relevant phenomena in creative cognition."
} 
whether non-human animals can be creative is not substantive or appropriate one for comparative psychology to address.

For my part, I believe that rejectionism and in particular strong rejectionism are views worth taking seriously. Allow me to stress that this is not in virtue of any commitment to human exceptionalism, let alone a "mysterian" or non-naturalistic view of the nature of human creativity (Hausman 1976). On the contrary, I think it likely that most of the basket of cognitive capacities and abilities we associate more or less strongly with the concept of creativity in humans can be found in abundant supply in a wide variety of non-human species. My concern is rather that the concept of creativity is too enmeshed in the vagaries of ordinary language and culturally- and contextspecific value judgements to be effectively applicable to non-human animals in scientific contexts. To offer an analogy, the Strong Rejectionist view is that creativity might be best considered comparable to everyday folk psychological concepts such as wit, charisma, or good taste rather than to scientific notions such as learning, memory, or (perhaps) intelligence. If this is correct, then we might wonder whether creativity is a concept we can reasonably do without, at least for the purposes of comparative psychology, even if it is likely to continue to play a role in folk psychology as well as - perhaps - human cognition research.

I recognise that this position is likely to be seen by many as provocative, not to mention under-motivated by the relatively brief arguments provided. I certainly grant that the considerations advanced in this paper are far from decisive and are at best suggestive of the idea that there may be something inadequate about our existing concept of creativity. I also regard any reasonable form of rejectionism as open to empirical disconfirmation; I do not rule out the possibility that some clear and convincing conceptual, psychometric, or neuroscientific basis for creativity as a unified phenomenon will be developed or discovered, for example, though I am far from optimistic in this regard.

However, I think Strong Rejectionism may offer a valuable path forward for comparative psychology, one that liberates it from dealing with vexed and perhaps unanswerable philosophical disputes. Note also that somewhat similar approaches have been successfully adopted in other areas of scientific psychology. Thus comparative psychologists investigating episodic memory have largely managed to sidestep worries about phenomenology by instead talking of "episodic-like memory", operationalised in terms of representations of specific places, times, and items (Clayton et al. 2003; Nairne 2015). Likewise, the study of human intelligence has benefitted by (at least in principle) abandoning attempts to provide a definitive account of intelligence per se, instead focusing on theoretical concepts such as "g-factor" (see footnote 11, above).

My suggestion, then, is that comparative psychology might do well to adopt a similar approach to creativity, focusing on developing operationalised and welldefined formulations of phenomena such as innovation, behavioural plasticity, and exploration, while explicitly repudiating the project of identifying these with our folk psychological concept of creativity. This approach will not remove all methodological issues, of course, and questions about how these phenomena relate to broader psychology notions like learning and intelligence will remain.

One might worry that we are simply 'moving the bump in the carpet', and that the same conceptual and methodological challenges that confound a science of creativity will likewise dog the study of these closely related notions. After all, as noted in the 
discussion in 4.2 above, concepts like novelty are scarcely more perspicuous than creativity. ${ }^{15}$ Nonetheless, I would suggest that by abandoning creativity as the singular object of our inquiry in favour of a more pluralistic approach we gain at least two key advantages.

First, insofar as we reject the idea that creative cognition per se is the object of our inquiry, we can adopt more thoroughly pluralistic typologies cutting across multiple dimensions of behavioral variability, without having to theorise about what conceptual quintessence they all have in common. Second, by framing our investigations within a relatively austere scientific vocabulary of concepts like behavioural plasticity, neophilia, exploration, and so on, we can free ourselves from the mesmeric folk psychological trappings of the concept of creativity and instead engage in operationalisation and stipulative definition of our various theoretical measures without scruples or deference to pretheoretical concepts. If a scientist tells us that a given animal's behaviour satisfies their definition of creativity, for example, we may be tempted to ask whether it is really creative in the broader sense of the term (and this, in my view, is where the trouble begins). By contrast, if the scientist were to provide a stipulative typology of forms of behavioural plasticity and show that the organism exhibited one or more of them, there is no equivalent question left dangling.

I would finally note that the proposal of rejecting creativity need not be as radical as it may first appear. If the foregoing considerations are correct, it need have little impact on the experimental study of divergent thinking, innovation, improvisation, and insight in non-human animals, and at most would advise that thinkers engaged in these domains of inquiry avoid the risk of mystification and conceptual obscurity by coupling their findings to terms like creativity and creative intelligence. And of course, insofar as creativity is a central concept in folk psychology and aesthetics, philosophical exploration of the normative and descriptive considerations governing its applicability across different cultures and within different domains of human life will continue to be valuable.

There is also the question of whether Strong Rejectionism of the type defended here need trouble human creative cognition researchers. While I wish to remain strictly speaking agnostic for present purposes as to this question, I would suggest that many of same worries about the concept of creativity in comparative psychology do equally apply to creative cognition research in humans. However, there are also some notable methodological differences, such as the existence of relatively uncontroversial exemplars of human creativity as well as (perhaps) considerations concerning our phenomenological access to creative experience. Thus, while I am sympathetic to a broader application of the Strong Rejectionist program to cognitive science tout court, that is a more ambitious proposal than I am prepared to take on here, and I confine my tentative defence of Strong Rejectionism for now at least to the non-human case. ${ }^{16}$

\footnotetext{
15 Thanks to both an anonymous reviewer and the members of the New York Philosophy of Perception Workshop for raising this concern.

${ }^{16}$ Though not addressed in this paper, I would briefly note that strong rejectionism might also be the best path for researchers in machine learning and artificial intelligence concerned with whether a computer or robot could be creative (Boden 2014). While we might reasonably hope to develop machines that can produce innovative and valuable outputs and respond flexibility and appropriately to changes in their environment, more narrowly conceptual problems of whether a machine can really be creative are arguably largely irrelevant to achieving these ends.
} 


\section{Conclusion}

The central argument of this paper has been there are great obstacles to applying the concept of creativity in comparative psychological research. I began by describing a selection of some of rich and varied accounts of creativity developed by philosophers and psychologists, before surveying some of the impressive displays of behaviour among animals we might be inclined to think of as demonstrating creative intelligence. I went on to outline some of the problems that dog attempts to apply existing theories of creativity in scientific contexts, noting that these already daunting problems are especially acute when moving from human to non-human animals. Noting possible strategies for overcoming these difficulties, I suggested that the best way forward for comparative psychology may be to abandon the concept of creativity entirely, not on the grounds that animals lack creative intelligence but because the concept is simply too mired in norms and conceptual vagaries to take flight.

Funding This work was supported by the Leverhulme Centre for the Future of Intelligence, Leverhulme Trust, under Grant RC-2015-067.

\section{Compliance with ethical standards}

Conflict of interest None.

Ethical approval Not applicable.

Informed consent Not applicable.

Open Access This article is licensed under a Creative Commons Attribution 4.0 International License, which permits use, sharing, adaptation, distribution and reproduction in any medium or format, as long as you give appropriate credit to the original author(s) and the source, provide a link to the Creative Commons licence, and indicate if changes were made. The images or other third party material in this article are included in the article's Creative Commons licence, unless indicated otherwise in a credit line to the material. If material is not included in the article's Creative Commons licence and your intended use is not permitted by statutory regulation or exceeds the permitted use, you will need to obtain permission directly from the copyright holder. To view a copy of this licence, visit http://creativecommons.org/licenses/by/4.0/.

\section{References}

Amabile, T. M. (1982). Social psychology of creativity: a consensual assessment technique. Journal of Personality and Social Psychology., 43, 997-1013. https://doi.org/10.1037/0022-3514.43.5.997.

Amabile, T. M. (1996). Creativity in context. London: Hachette UK.

Arden, R., Chavez, R. S., Grazioplene, R., \& Jung, R. E. (2010). Neuroimaging creativity: a psychometric view. Behavioural Brain Research., 214, 143-156. https://doi.org/10.1016/j.bbr.2010.05.015.

Audi, R. (2018). Creativity, imagination and intellectual virtue. In M. Kieran \& B. Gaut (Eds.), Creativity and philosophy (pp. 25-43). London: Routledge.

Auersperg, A. M. I. (2015). Chapter 3 - exploration technique and technical innovations in Corvids and parrots. In Animal creativity and innovation, edited by Allison B Kaufman and James C Kaufman, 45-72. Explorations in Creativity Research. San Diego: Academic Press. https://doi.org/10.1016/B978-0-12800648-1.00003-6. 
Auersperg, A. M. I., Kacelnik, A., \& von Bayern, A. M. P. (2013). Explorative learning and functional inferences on a five-step means-means-end problem in Goffin's cockatoos (Cacatua Goffini). PLoS One, 8, e68979. https://doi.org/10.1371/journal.pone.0068979.

Bateson, P., \& Martin, P. (2011). Play, playfulness, creativity and innovation. Play, playfulness, creativity and innovation. Cambridge University Press. https://doi.org/10.1017/CBO9781139057691.

Baumeister, Roy, Brandon Schmeichel, C DeWall, and Kathleen Vohs. (2011). Is the conscious self a help, a Hindrance, or an Irrelevance to the Creative Process? 53 (April).

Birch, J., \& Okasha, S. (2015). Kin selection and its critics. BioScience, 65(1), 22-32. https://doi.org/10.1093/ biosci/biu196.

Bird, C. D., \& Emery, N. J. (2009a). Insightful problem solving and creative tool modification by captive nontool-using rooks. Proceedings of the National Academy of Sciences of the United States of America., 106, 10370-10375. https://doi.org/10.1073/pnas.0901008106.

Bird, C. D., \& Emery, N. J. (2009b). Rooks use stones to raise the water level to reach a floating worm. Current Biology, 19, 1410-1414. https://doi.org/10.1016/j.cub.2009.07.033.

Boden, M. A. (1996). Creativity. In Artificial Intelligence, 267-91. Elsevier. https://doi.org/10.1016/B978012161964-0/50011-X.

Boden, M. A. (2004). The creative mind: Myths and mechanisms. Routledge.

Boden, M. A. (2010). Creativity and art: Three roads to surprise. Oxford University Press.

Boden, M. A. (2014). The philosophy of creativity. In In The Philosophy of Creativity, edited by Elliot Samuel Paul and Scott Barry Kaufman. Oxford University: Press. https://oi.org/10.1093/acprof:oso/ 9780199836963.001 .0001$.

Call, J., \& Tomasello, M. (2008). Does the chimpanzee have a theory of mind? 30 years later. Trends in Cognitive Sciences, 12(5), 187-192. https://doi.org/10.1016/j.tics.2008.02.010.

Campbell, D. T. (1960). Blind variation and selective retentions in creative thought as in other knowledge processes. Psychological Review, 67(6), 380-400. https://doi.org/10.1037/h0040373.

Carruthers, P., \& Picciuto, E. (2014). The origins of creativity. In The Philosophy of Creativity, edited by E Paul and S Kaufman. Oxford University: Press.

Chen, M. (2018). Criterial problems in creative cognition research. Philosophical Psychology, 31(3), 368-382. https://doi.org/10.1080/09515089.2017.1422486.

Clayton, N. S., Bussey, T. J., \& Dickinson, A. (2003). Can animals recall the past and plan for the future? Nature Reviews Neuroscience, 4(8), 685-691. https://doi.org/10.1038/nrn1180.

Darwin, C. (1880). Descent of man, and selection in relation to sex. New York, NY: D. Appleton and Company.

Deary, I. J. (2000). Looking down on human intelligence: From psychometrics to the brain (Vol. 34). Oxford University Press.

Durstewitz, D., Vittoz, N. M., Floresco, S. B., \& Seamans, J. K. (2010). Abrupt transitions between prefrontal neural ensemble states accompany behavioral transitions during rule learning. Neuron., 66, 438-448. https://doi.org/10.1016/j.neuron.2010.03.029.

Epstein, R., Lanza, R. P., \& Skinner, B. F. (1981). "Self-Awareness" in the Pigeon. In 'Self-awareness' in the pigeon. Science. https://doi.org/10.1126/science.212.4495.695.

Epstein, R., Kirshnit, C. E., Lanza, R. P., \& Rubin, L. C. (1984). 'Insight' in the pigeon: antecedents and determinants of an intelligent performance. Nature., 308, 61-62. https://doi.org/10.1038/308061a0.

Feist, G. J. (1998). A Meta-analysis of personality in scientific and artistic creativity. Personality and Social Psychology Review, 2(4), 290-309. https://doi.org/10.1207/s15327957pspr0204_5.

Finke, R. A, Ward, T. B., \& Smith, S. M. (1992). Creative Cognition: theory, research, and applications.

Fuentes, A. (2017). The creative spark: How imagination made humans exceptional. New York, NY, US: Dutton.

Gaut, B. (2003). Creativity and imagination. In B. Gaut \& P. Livingston (Eds.), The creation of art: New essays in philosophical aesthetics (pp. 148-173). New York: Cambridge University Press.

Gaut, B. (2010). The philosophy of creativity. Philosophy Compass, 5(12), 1034-1046. https://doi.org/10. 1111/j.1747-9991.2010.00351.x.

Gaut, B., \& Kieran, M. (2018). Creativity and philosophy. Creativity and Philosophy. Routledge. https://doi. org/10.4324/9781351199797.

Greenberg, R., \& Mettke-hofmann, C. (2001). Ecological aspects of Neophobia and Neophilia in birds. In Current Ornithology, 16. https://doi.org/10.1007/978-1-4615-1211-0_3.

Guilford, J. P. (1967). The nature of human intelligence.

Güzeldere, G. (1997). The many faces of consciousness: a field guide. In In The Nature of Consciousness: Philosophical Debates, edited by Ned Block, Owen Flanagan, and Güven Güzeldere, 1-68. Cambridge: MA.

Hadamard, J. (1954). An essay on the psychology of invention in the mathematical field. Courier Corporation. 
Hanus, D., Mendes, N., Tennie, C., \& Call, J. (2011). Comparing the performances of apes (gorilla gorilla, pan troglodytes, Pongo Pygmaeus) and human children (homo sapiens) in the floating Peanut task. PLoS One, 6(6), e19555. https://doi.org/10.1371/journal.pone.0019555.

Hausman, C. R. (1976). Introduction: the Creativity Question. In The creativity question, edited by Carl R. Hausman and Albert Rothenberg, 3-26. Duke University Press.

Heinrich, B. (1995). An experimental investigation of insight in common ravens (Corvus Corax). The Auk., 112, 994-1003. https://doi.org/10.2307/4089030.

Hennefield, L., Hwang, H. G., \& Povinelli, D. J. (2019). Going Meta: retelling the scientific retelling of Aesop's the crow and the pitcher. Journal of Folklore Research., 56, 45. https://doi.org/10.2979/jfolkrese.56.2_3.04.

Hills, A., \& Bird, A. (2018). Creativity without value. In M. Kieran \& B. Gaut (Eds.), Creativity and philosophy (pp. 95-107). London: Routledge.

Hinde, R. A., \& Fisher, J. (1951). Further observations on the opening of Milk bottles by birds. British Birds., 169, 1006. https://doi.org/10.1038/1691006a0.

Hutchinson, E. D. (1941). The nature of insight. Psychiatry (New York). Vol. 4. MIT Press. https://doi.org/10. 1521/00332747.1941.11022320.

Jelbert, S. A., Taylor, A. H., Cheke, L. G., Clayton, N. S., \& Gray, R. D. (2014). Using the Aesop's fable paradigm to investigate causal understanding of water displacement by new Caledonian crows. PLoS One, 9(3), e92895. https://doi.org/10.1371/journal.pone.0092895.

Kant, I. (1987). Critique of judgment. Hackett Publishing.

Kaufman, J. C., \& Beghetto, R. A. (2009). Beyond big and little: the four C model of creativity. Review of General Psychology, 13(1), 1-12. https://doi.org/10.1037/a0013688.

Kaufman, J. C., \& Kaufman, A. B. (2004). Applying a creativity framework to animal cognition. New Ideas in Psychology, 22(2), 143-155. https://doi.org/10.1016/j.newideapsych.2004.09.006.

Kaufman, A. B., \& Kaufman, J. C. (2015). Animal creativity and innovation. Academic Press.

Kaufman, S. B., \& Paul, E. S. (Eds.). (2014). The philosophy of creativity: New essays. New York: Oxford University Press. https://doi.org/10.1093/acprof:oso/9780199836963.001.0001.

Kaufman, A. B., Butt, A. E., Kaufman, J. C., \& Colbert-White, E. N. (2011). Towards a neurobiology of creativity in nonhuman animals. Journal of Comparative Psychology, 125, 255-272. https://doi.org/10. 1037/a0023147.

Kawai, M. (1965). Newly-acquired pre-cultural behavior of the natural troop of Japanese monkeys on Koshima islet. Primates., 6, 1-30. https://doi.org/10.1007/BF01794457.

Kharkhurin, A. V. (2014). Creativity.4in1: four-criterion construct of creativity. Creativity Research Journal, 26(3), 338-352. https://doi.org/10.1080/10400419.2014.929424.

Koestler, A. (1964). The act of creation. New York: Penguin Books.

Köhler, W. (1925). In E. Winter (Ed.), The mentality of apes. New York, NY, US: Vintage Books.

Kolodny, O., Edelman, S., \& Lotem, A. (2015). Evolved to adapt: A computational approach to animal innovation and creativity. Current Zoology, 61(2), 350-367. https://doi.org/10.1093/czoolo/61.2.350.

Kounios, J., \& Beeman, M. (2009). The Aha! Moment: The cognitive neuroscience of insight. Current Directions in Psychological Science, 18(4), 210-216. https://doi.org/10.1111/j.1467-8721.2009.01638.x.

Kronfeldner, M. E. (2009). Creativity naturalized. The Philosophical Quarterly, 59(237), 577-592. https://doi. org/10.1111/j.1467-9213.2009.637.x.

Kronfeldner, M. (2018). Explaining creativity. In B. Gaut \& M. Kieran (Eds.), Routledge handbook on creativity and philosophy (pp. 213-229). New York: Routledge.

Kuczaj, S. A. (2017). Animal creativity and innovation. In APA Handbook of Comparative Psychology: Perception, Learning, and Cognition., 627-41. American Psychological Association. https://doi.org/10. 1037/0000012-028.

Mednick, S. A. (1968). The remote associates test. The Journal of Creative Behavior., 2, 213-214. https://doi. org/10.1002/j.2162-6057.1968.tb00104.x.

Mendes, N., Hanus, D., \& Call, J. (2007). Raising the level: orangutans use water as a tool. Biology Letters, 3 , 453-455. https://doi.org/10.1098/rsbl.2007.0198.

Morriss-Kay, G. M. (2010). The evolution of human artistic creativity. Journal of Anatomy, 216, 158-176. https://doi.org/10.1111/j.1469-7580.2009.01160.x.

Nairne, J. S. (2015). The three 'Ws' of episodic memory: what, when, and where. American Journal of Psychology, 128(2), 267-279. https://doi.org/10.5406/amerjpsyc.128.2.0267.

Novitz, D. (1999). Creativity and constraint. Australasian Journal of Philosophy, 77(1), 67-82. https://doi.org/ $10.1080 / 00048409912348811$.

Paul, E. S., \& Stokes, D. (2018). Attributing creativity. In Creativity and philosophy, edited by Berys Gaut and Matthew Kieran. Routledge. 
Poincaré, H. (1952). Mathematical creation. In The creative process: A symposium, edited by Brewster Ghiselin, 34 -42. New York: Mentor.

Pressing, J. (1988). Improvisation: Methods and models. In Generative processes in music: The psychology of performance, improvisation, and composition (pp. 129-178). New York, Clarendon Press/Oxford University Press.

Prinz, J. (2007). The emotional construction of morals. Oxford University Press.

Pryor, K. (1999). Don't shoot the dog!: The new art of teaching and training. Bantam.

Pryor, K. (2000). Lads before the wind. Sunshine Books.

Pryor, K. W., Haag, R., \& O'Reilly, J. (1969). The creative Porpose: training for novel behavior. Journal of the Experimental Analysis of Behavior., 12, 653-661. https://doi.org/10.1901/jeab.1969.12-653.

Reader, S. M., \& Laland, K. N. (2003). Animal Innovation (Vol. 10). Oxford University Press Oxford.

Rosch, E. (1973). On the internal structure of perceptual and semantic categories. Cognitive Development and the Acquisition of Language.

Russ, S. W. (1993). Affect and creativity. New York: Erlbaum.

Russon, A. E., Kuncoro, P., Ferisa, A., \& Handayani, D. P. (2010). How orangutans (Pongo Pygmaeus) innovate for water. Journal of Comparative Psychology, 124, 14-28. https://doi.org/10.1037/a0017929.

Russon, A. E., Kuncoro, P., \& Ferisa, A. (2015). Chapter 15 - tools for the trees: Orangutan arboreal tool use and creativity. In Animal Creativity and Innovation, edited by Allison B Kaufman and James C Kaufman, 419-58. Explorations in Creativity Research. San Diego: Academic Press. https://doi.org/10.1016/B9780-12-800648-1.00015-2.

Rutz, C., Sugasawa, S., van der Wal, J. E. M., Klump, B. C., \& St Clair, J. J. H. (2016). Tool bending in new Caledonian crows. Royal Society Open Science, 3(8), 160439. https://doi.org/10.1098/rsos.160439.

Schiller, P. H. (1957). Innate motor action as a basis of learning: Manipulative patterns in the chimpanzee. In C. M. Schiller (Ed.), Instinctive behaviour (pp. 264-287). New York, International Universities Press.

Serpico, D. (2018). What kind of kind is intelligence? Philosophical Psychology, 31(2), 232-252. https://doi. org/10.1080/09515089.2017.1401706.

Shettleworth, S. (2010). Cognition, evolution, and behavior. Second edi. New York, Oxford University Press.

Shettleworth, S. J. (2012). Do animals have insight, and what is insight anyway? Canadian Journal of Experimental Psychology., 66, 217-226. https://doi.org/10.1037/a0030674.

Shevlin, H. (2020). Current controversies in the cognitive science of short-term memory. Current Opinion in Behavioral Sciences, 32, 148-154. https://doi.org/10.1016/j.cobeha.2020.02.005.

Silvia, P. J. (2007). An introduction to multilevel modeling for research on the psychology of art and creativity. Empirical Studies of the Arts., 25, 1-20. https://doi.org/10.2190/6780-361t-3j83-0411.

Simonton, D. K. (2009). Chapter four. Creativity as a Darwinian phenomenon: The blind-variation and selective-retention model. In The Idea of Creativity, edited by Karen Bardsley, Denis Dutton, and Michael Krausz. Leiden, The Netherlands: Brill.

Spearman, C. (1927). The abilities of man (Vol. 89) Macmillan New York.

Sugiyama, Y., \& Koman, J. (1979). Tool-using and -making behavior in wild chimpanzees at Bossou, Guinea. Primates, 20(4), 513-524. https://doi.org/10.1007/BF02373433.

Tan, W. H., Tsai, C. G., Lin, C., \& Lin, Y. K. (2014). Urban canyon effect: storm drains enhance Call characteristics of the Mientien tree frog. Journal of Zoology, 294, 77-84. https://doi.org/10.1111/jzo.12154.

Taylor, A. H., Elliffe, D., Hunt, G. R., \& Gray, R. D. (2010). Complex cognition and behavioural innovation in new Caledonian crows. In Proceedings of the Royal Society B: Biological Sciences., 277, 2637-2643. https://doi.org/10.1098/rspb.2010.0285.

Thorndike, E. (1911). Animal Intelligence: Experimental Studies. New York: The MacMillan Company.

Torrance, E. P. (1980). Growing up creatively gifted: A 22-year longitudinal study. The Creative Child and Adult Quarterly.

Wallas, G. (1926). The art of thought. New York, NY, US: Harcourt, Brace \& Company.

Ward, T. B., Smith, S. M., \& Finke, R. A. (1999). Creative cognition. Handbook of Creativity, 189, 212.

Weir, A. A. S., Chappell, J., \& Kacelnik, A. (2002). Shaping of hooks in new Caledonian crows. Science., 297, 981. https://doi.org/10.1126/science.1073433.

Weisberg, R. W. (2015). On the usefulness of 'value' in the definition of creativity. Creativity Research Journal, 27(2), 111-124. https://doi.org/10.1080/10400419.2015.1030320.

Publisher's note Springer Nature remains neutral with regard to jurisdictional claims in published maps and institutional affiliations. 